Sustainability 2009, 1, 1323-1330; doi:10.3390/su1041323

\title{
Astrobiology, Sustainability and Ethical Perspectives
}

\author{
Jacques Arnould \\ CNES, French Space Agency, 2 place Maurice Quentin, F-75039 Paris, Cedex 01, France; \\ E-Mail: jacques.arnould@cnes.fr; Tel.: +33 1447675 20; Fax: +33 144767950 \\ Received: 5 November 2009 / Accepted: 8 December 2009 / Published: 15 December 2009
}

\begin{abstract}
Astrobiology, a new field of research associating the prospects and constraints of prebiotic chemistry, mineralogy, geochemistry, astrophysics, theoretical physics, microbial ecology, etc., is assessed in terms of sustainability through the scientific and social functions it fulfils, and the limits it encounters or strives to overcome. In the same way as sustainable development, astrobiology must also take into account the temporal dimension specific to its field of investigation and examine its underlying conception of Nature.
\end{abstract}

Keywords: astrobiology, sustainability, precautionary principle, cultural theory

\section{Introduction}

French-speakers have difficulty using and undoubtedly understanding the term sustainability, and the translation most commonly used in French, "durabilité", is not entirely adequate. But while English-speakers have a certain advantage in this regard, their claim on the term must not cause its use to be overly restricted. Naturally, current use of the term is very closely tied to development and the environment, since the definition of sustainable development as "development that meets the needs of the present without compromising the ability of future generations to meet their own needs" by the World Commission on the Environment and Development (Brundtland report, 1987). Yet we must not forget that the notion of sustainability can be applied to other fields, and even to other prospects. Indeed, the philosopher Andrew Gaines explains how "a passive and ignorant citizenry will never create a sustainable world", while Arie de Geus, a former executive at Royal Dutch Shell, now associate professor at the London School of Economics and member of the board of the Center for Organizational Learning at MIT, applies the term to the world of business: "The ability to learn faster than your competitors may be the only sustainable competitive advantage." 
Considering the diverse ways in which the term is used, two conclusions can be drawn. First, there appears to be no reason not to examine the sustainable nature of the field of research known today as astrobiology. Moreover, and this is the second conclusion, it is important not to restrict the notion of sustainability to its use with regard to the environment and sustainable development; it would appear obvious that a company which, to quote Arie de Geus, has a "sustainable competitive advantage" is not necessarily contributing to sustainable development in its region or country!

Thus, having said this, which notion of sustainability will I use here? I have chosen to draw on that introduced by the Brundtland report. After the definition provided above, the text continues as follows: "It contains within it two key concepts: the concept of needs, in particular the essential needs of the world's poor, to which overriding priority should be given, and the idea of limitations imposed by the state of technology and social organisation on the environment's ability to meet present and future needs." Needs and limitations: we shall use these two concepts to examine research in astrobiology, before returning to the question of how this research treats time, for both humans and nature.

\section{Need}

\subsection{The Needs of Science}

Does scientific research need astrobiology? This may seem an incongruous question, especially for those familiar with the quality of the scientists and the prestige of the organisations involved in this new field. The unusual nature of the field (that is, the interest in the reality of extraterrestrial life, which is yet to be discovered or observed) should not cast any doubt on the legitimacy of its assertions, methods or results, nor associate it with other disciplines which may end in -logy (astrology, scientology, etc.) but cannot claim to be "scientific" in the generally accepted meaning of the word. To illustrate the scientific merit of the field, beyond arguing its academic and institutional honourability and authority, one could easily point out the relevance of the results and related publications which now fall within the scope of astrobiology. Examples which come readily to mind include the discovery and study of extremophiles, research in geobiological dynamics, geoclimatic studies, etc. Alongside, or rather beyond, these arguments in support of astrobiology, an additional aspect must be mentioned, which I am keen to refer to as the post-Darwin perspective.

For the past century and a half (The Origin of Species was published in 1859), the theory developed by Charles Darwin has revolutionised the way we consider and understand life, not only from a scientific perspective, but also from a philosophical, theological and cultural point of view. In reality, it has probably raised as many questions as it has provided answers to human wonderings about themselves and the species around them. Thus the extent to which chance, contingency and determinism are involved in the evolution of life remains a subject of intense research and fierce debate. Since we cannot rewind the movie of life's evolution on Earth, if we could find another movie playing out elsewhere than on our planet, and if we could compare the two, we would perhaps be able to see what could have been different (which would support the contingency hypothesis) or, on the contrary, see that, with only slight differences, what is could not have been otherwise (which would seem to support strong determinism). There is little use in discussing the epistemological and 
philosophical impact of this post-Darwin perspective at a time when our societies, on both sides of the Atlantic, are confronted with claims based in creationism and intelligent design.

\subsection{The Need for Science}

Astrobiology is useful to science and human thinking in general, but might it also be useful to our societies? Going back to the expressions borrowed from the notion of sustainable development, is astrobiology economically viable and socially equitable? Or, in more explicit terms, is it reasonable, appropriate and acceptable to spend part of our national and international budgets on astrobiological research rather than devoting these funds to those to whom the Brundtland report refers as "the world's poor"? This eternal question no longer comes as a surprise to those working in the space sector, but nevertheless cannot be overlooked.

Indeed, while it is easy enough to demonstrate and even defend the utility of technical space programmes for the construction, launch and supply of observation, communication or positioning satellites, it may seem another matter altogether to justify the allocation of funds to scientific programmes aimed at better understanding the universe. The greatest sceptics, who also claim to be the most realistic, ask: what is the point of sending probes throughout the solar system, installing costly telescopes beyond the Earth's atmosphere to relay images of outer space, and (the critics' favourite target) continuing to dream of setting foot on Mars when for the past forty years, Man's adventure in space has been reduced to endlessly touring the suburbs of Earth? In short, it would appear that presenting astrobiology as one of our societies' needs is no easy task. And yet...

I will refrain here from pleading in favour of theoretical science, contenting myself with simply saying that the question of the plurality of worlds, the epistemological forerunner of astrobiology, belongs to an era, or better, to a tradition in which theory is given priority over practice and technique. This means contemplating and wondering before acting, practicing and, in fact, dominating. Without questioning the quality and necessity of the link modernity has created between sciences and techniques, I do think it is important in our societies to maintain a form of science which is more theoretical than immediately useful. In fact I am convinced that this is essential to the sustainability of our societies, and a means of preparing them for the future. Astrobiology, like other scientific fields (the "neighbouring" field of astronomy, the "symmetrical" science of the infinitely small, and certain social sciences), is a means of honouring this aspect of humanity's intellectual commitment.

I would also add that astrobiology could play a part in increasing interest in sciences among the younger generations. Indeed, the lack of interest in sciences among young people is a recognised reality in our Western societies, the consequences of which are only partially foreseeable. Must we simply throw up our hands? On the contrary, I think we could first draw on fields other than the technical sciences to create appeal for scientific research. While it has become urgent to provide scientists with an acceptable socio-economic standing in our societies, we must also acknowledge and foster the very human element of curiosity which is expressed through science. In asking whether other life forms exist elsewhere than on Earth, forms different from those known to us, is astrobiology not a unique way of honouring this curiosity? Considering the debates our forefathers held on the subject, and then the success of science fiction literature among the general public for the past several centuries, the 
answer is clearly "yes". Thus I am convinced that because our societies do need science, they must take astrobiology seriously and invest in it.

\section{Limitations}

\subsection{The Limits of Knowledge}

The Brundtland report employs the notion of limits and limitations, in terms of those "imposed by the state of technology and social organisation on the environment's ability to meet present and future needs." It is not difficult to transpose to science this use of the concept of limits, as applied to natural resources. In the case of astrobiology, the limits can be identified quite easily.

Scientists are well aware of our telescopes' ability to search the skies for any signals that may be emitted in space, and the technical solutions available for reaching ever further frontiers. The patient quest and recent discovery of exoplanets is an excellent example of the progress which is possible and permitted by the alliance of scientists and engineers. In the field of the infinitely small, the efforts undertaken to build the LHC, and the American authorities' decision to abandon the Super Superconducting Collider (SSC) project in the early 1990s, illustrate both the scale of financial investment and the limits for which present-day governments are prepared.

There are other boundaries which must not be overlooked, such as those existing in the human mind. The most obvious, when it comes to astrobiology, is undoubtedly the difficulty of defining life itself, not only the life we are looking for elsewhere in the solar system or throughout the universe, but even life as we know it on Earth. For as long as philosophy has existed, one could say, it has been confronted with this challenge, and now scientists developing astrobiology programmes must also grapple with this question. Here, it is worth remembering the debates which preceded the Viking expeditions to Mars in the early 1970s, James Lovelock's proposal for a global study of the red planet which led to his development of the Gaia theory, the discovery of terrestrial extremophiles, not to mention the very Earthly debates on the subjects of abortion and euthanasia. Indeed, whether human, terrestrial or extraterrestrial, life continues to be something elusive and indefinable, which, when you think about it, has the effect of stimulating research in astrobiology.

While my analysis here is by no means exhaustive, I do wish to discuss one last boundary, which is that of anthropocentrism. The three successive revolutions brought about by the modern sciences (Copernican, Darwinian and Freudian) have changed the way humans perceive themselves within the cosmic and biological reality, but they have not allowed humanity to break with what convention qualifies as anthropocentrism. The work of Copernicus, Galileo and modern astronomers resulted in the replacement of the Closed World of ancient times with an infinite universe whose centre is everywhere and which has no circumference. Yet, due more to its limits than its abilities, humanity has still continued to view the world through its own small window: humanity has become a centre among other possible centres.

The limits in question here can be summed up in the words of Niels Bohr with regard to quantum physics, but which can be applied to all scientific disciplines: "There is no quantum world. There is only an abstract physical description. It is wrong to think that the task of physics is to find out how 
nature is. Physics concerns what we can say about nature" [1]. This certainly holds true for astrobiology.

\subsection{Knowing the Limits}

Any science or scientific practice must measure its limits, whatever they may be; this is essential to its sustainability, not only for it to be carried out reasonably and achieve true results, but also to bring about real progress. In other words, it is a question of rightly applying the precautionary principle.

Precaution has emerged as a principle and is a current trend, but above all it is a moral virtue applying well beyond the sciences. Martine Rémond-Gouilloud has defined it as follows: "If in doubt, do not abstain, but proceed as if the risk were proven" [2]; in other words, in the absence of scientific certainty regarding specific dangers or odds, waste no time in adopting appropriate and justified preventive measures. The precautionary principle does not specify the content of these measures any more than it imposes what they must be; the measures must simply be proportionate and acceptable. Understood and interpreted in this way, the precautionary principle does not so much define and impose specific obligations as maintain the sense that uncertainty and risk are still relevant questions for our societies. This principle is necessary, Jean-Jacques Salomon explains, "in a world in which science allows the dream that anything possible is desirable because it can be realised" [3]. Thus, in my view, it would be wrong to understand the precautionary principle as necessarily prohibitive, or as constant resistance to progress in the sciences. Rather, it should be seen as a systematic response to imagination, speculation and hypothesis, and as a consistently sceptical attitude: in its own way, precaution helps make science sustainable. Thus, science appears as an approach based less on certainty than on the suspicions and doubts it is able to raise about what human intelligence can or cannot (yet) know.

Viewed in this light, the precautionary principle allows for the possibility of risk taking... and may even invite it. In The Phenomenology of Mind, Hegel sees risk as fundamental to the process by which a human being becomes aware of his self and free will: "The individual who has not risked his life may admittedly be recognized as a person [in the legal and abstract sense of the word, without effective determination in reality], but he has not achieved the truth of being recognised as a self-sufficient self-consciousness." [4] Thus, not only is the human an animal bound to take risk, but risk is an essential aspect of his constitution and construction in the sense that it is hinged on the specifically human ability, and necessity, of choice.

As a scientific approach in its own right, astrobiology is not exempt from the precautionary principle as I have presented it here, especially as it is a field which does involve taking risks. There are risks of a technical nature (the issues of planetary contamination and protection come to mind, in particular [5]), as well as those of a philosophical and psychological nature, just as real, which would come with the potential discovery of other forms of life, or even intelligence: with its cultures, ideologies and beliefs, is humanity ready to discover that it is not alone in the universe, however far away these extraterrestrial beings may be in space and time? One could say without exaggeration that astrobiology lies at a cusp which, if surpassed, or transgressed if you will, would to some minds cross 
over into the realm of the sacred! This is actually one of astrobiology's greatest merits, as well as an invitation not to exclude ethical and philosophical reflection from this field of research.

\section{Generations}

\subsection{The Nature of Generations}

One criteria of sustainability is the consideration of time; indeed, the definition of sustainable development set out in the Brundtland report includes the consideration of present and future generations, and current and future needs. In reality, astrobiology probably does not need to pay as much attention to this dimension, although when it comes to developing a scientific programme in the field, common sense dictates that it should be planned for a potentially long duration: indeed, the study of possible extraterrestrial life forms may occupy researchers for many generations to come!

The subject of generations also touches on a specific feature of astrobiology, which is the close link between space and time. As we know, whenever human intelligence, science, and curiosity are focused on the universe, they must take into account an astronomical property: the link between measurements of space and time. The farther information travels to reach us, the older this information is when we receive it, just as a signal takes proportionally more time to reach its target the farther the target is from the emitter. What this means in natural science terms is that the objects and events which our eyes or instruments allow us to discover and observe do not necessarily appear in the form of remains or fossils - in the form of a past, dead reality — but may also appear in differed mode: today we may observe a living reality, an active process, as it appeared millions or even billions of years ago. Conversely, the information and signals we emit today throughout the universe could very well reach other worlds, other living beings, other forms of intelligence after the passing of several of our generations, or even after the disappearance of our species.

Taking this type of property into account is not necessarily easy, nor apparently useful; yet it represents a distinct aspect of the universe which, insofar as life is involved, cannot be ignored because time is not measured by the same scales in biology, geology, or astronomy. Shall we call this a form of relativity? In any case, to avoid damaging the credibility of astrobiology, this consideration must be incorporated into the way we understand, interpret, communicate and teach the fields' objectives and results.

\subsection{The Generations of Nature}

In the event that other life forms were discovered in space and time not so far from our own, the sustainability of astrobiology could be faced with the ultimate challenge: choosing which attitude to take towards these extraterrestrial beings and environments. Unless they were radically different from what we are or know (but in this case, would we even be able to discover and study them?), they would follow the rule that "nature cannot step twice into the same river", meaning in terms of the processes of transformation and evolution, and the characteristics of change and instability which are specific to our planet. 
As we know, throughout time, depending on cultures and circumstances, human societies have acted differently, and have contemplated and understood nature in diverse ways. Cultural theory distinguishes four myths of nature, illustrated by four figures [6]. Each figure represents a ball which can move across a surface of varying degrees of flatness; the ball's equilibrium or (lack of equilibrium) represents nature's reactions to human behaviour. Nature capricious is an unpredictable world ruled by chance: the ball moves randomly on a flat surface. Humanity has no power over nature and must content itself with a fatalistic "oh well" attitude. Nature perverse/tolerant has a homeostatic ability: the ball rolls over a concave surface with a convex summit. Thus, there is a considerable margin of tolerance and equilibrium, but if the impact is too strong, the ball passes over the lip and the balance is lost. James Lovelock, with his Gaia hypothesis, supports this understanding of nature which calls for "paying attention". Nature benign offers a constant balance: the ball is at the bottom of a deep concave surface; no matter what happens, it always comes back to the bottom. Nothing can really endanger this type of nature, which allows an entirely "laissez-faire" attitude. Lastly, nature ephemeral is in a precarious balance, which can be broken by the slightest impact: the ball is at the top of a convex surface. The attitude corresponding to this vision of nature is "don't touch anything".

Figure 1. Four myths of nature. Thompson et al. [6].

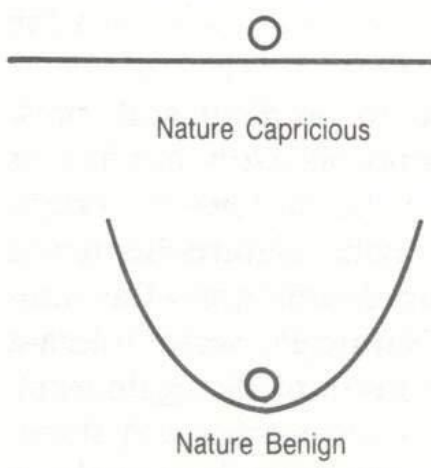

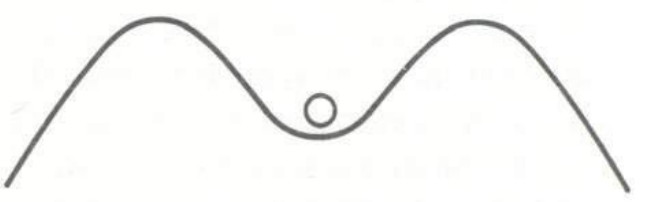

Nature Perverse/Tolerant

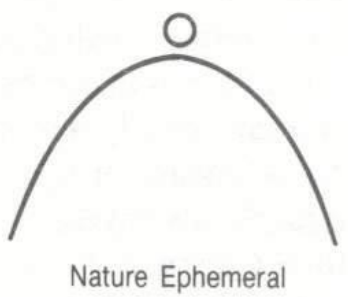

How can these results of cultural theory be applied here? They clearly show how we see nature and behave towards it, but does this make them options for the future? I do not think so. Even if the extraterrestrial biospheres that we could discover and explore were very different from ours, should we not automatically defend the idea that we must be respectful towards them, and even assume an attitude of conservation and preservation. Especially if our efforts to discover them have been long, persistent and costly. For astrobiology, this question remains theoretical, but it is already relevant in the space sector with regard to the physical and chemical pollution of Earth-orbits.

\section{Conclusions}

Humanity today is at a fascinating and delicate stage in its history-fascinating and delicate because after thousands or even millions of years of peregrination and expansion, it has reached the 
geographical frontiers of its planet and at the same time begun to realise the limits in terms of natural resources such as raw materials and energy. To the phenomenon of globalisation which is allowing humans to comprehend and construct the dynamic unit which is their species, the challenge of sustainable development adds an undeniably dramatic tone.

As "exotic" as astrobiology may seem on the surface, it does not escape the need for sustainability. Like any scientific discipline, it must consider the needs and limits not only of the community of researchers or science in general, but also of the human society as a whole; moreover, it must continually assess the respect for the realities it seeks to discover. This responsibility is even greater for this recent field of research as it is part of a long tradition which is not just scientific but also philosophical and cultural; this tradition, in exploring the possible existence of intelligent life forms other than humans, gives humanity a self-awareness which, I do not doubt, is the source of its unique sustainability.

\section{References and Notes}

1. Petersen, A. The philosophy of Niels Bohr. Bull. Atom. Sci. 1963, 19, 10.

2. Le Principe de Précaution dans la Conduite des Affaires Humaines; Godard, O., Ed.; Editions de la Maison des Sciences de 1'Homme/Institut National de la Recherche Agronomique: Paris, France, 1997; p. 119.

3. Salomon, J.J. Survivre à la Science. Une Certaine Idée du Futur; Albin Michel: Paris, France, 2000; p. 303.

4. Hegel, G.W.F. Phénoménologie de l'Esprit; Aubier: Paris, France, 1939; p. 159.

5. COSPAR Planetary Protection Policy (updated July 2008); In La Pollution Spatiale sous Surveillance; Alby, F., Arnould, J., Debus, A., Eds.; Ellipse: Paris, France, 2008; Available online: http://cosparhq.cnes.fr/Scistr/PPPolicy(20-July-08).pdf (accessed on 12 December 2009).

6. Thompson, M.; Ellis, R.; Wildavsky, A. Cultural Theory; Westview Press: Boulder, CO, USA, 1990; p. 27.

(C) 2009 by the authors; licensee Molecular Diversity Preservation International, Basel, Switzerland. This article is an open-access article distributed under the terms and conditions of the Creative Commons Attribution license (http://creativecommons.org/licenses/by/3.0/). 